УДК 551.462:551.463:551.464

\title{
АКУСТИЧЕСКИЕ ИССЛЕДОВАНИЯ ГЛУБОКОВОДНЫХ ГАЗОВЫХ ФАКЕЛОВ ОХОТСКОГО МОРЯ
}

Черных Денис Вячеславович1, denis.chernykh.vl@gmail.com

Саломатин Александр Сергеевич 1 , salomatin@poi.dvo.ru

Юсупов Владимир Исаакович2, iouss@yandex.ru

\section{Шахова Наталья Евгеньевна ${ }^{1,3}$,} nataliafletcher@yahoo.com

Космач Денис Алексеевич ${ }^{1}$, den-kosmach@mail.ru
Гершелис Елена Владимировна 4 , elenapanova@tpu.ru

Силионов Вячеслав Игоревич 1 , truexenox@gmail.com

Ананьев Роман Александрович 5 , corer@mail.ru

Гринько Андрей Алексеевич 4 , grinko@tpu.ru

Семилетов Игорь Петрович1,4, ipsemiletov@alaska.edu

Дударев Олег Викторович1, dudarev@poi.dvo.ru

1 Тихоокеанский океанологический институт им. В.И. Ильичева,

Россия, 690041, г. Владивосток, ул. Балтийская, 43.

2 Институт фотонных технологий ФНИЦ «Кристаллография и фотоника» РАН, Россия, 119333, г. Москва, Ленинский пр., 59.

3 Институт экологии Высшей школы экономики, Россия, 101000, г. Москва, ул. Мясницкая, 20.

4 Национальный исследовательский Томский политехнический университет, Россия, 634050, г. Томск, пр. Ленина, 30.

5 Институт океанологии им. П.П. Ширшова РАН, Россия, 117997, г. Москва, Нахимовский пр., 36.

Актуальность. Газовые фракелы - области пузырьковой эманации природных газов из морского дна в водную толщу и атмосфреру - обнаружены в Мировом океане на глубинах от десятков метров до нескольких километров. Прямые измерения проб газа, переносимого всплывающими пузырьками, показали, что в их составе содержится более 80 \% метана - второго по значимости парникового газа. Атмосфрерная эмиссия метана за счет расконсервирования гидратов и других депозитов природных углеводородов может приобрести широкомаситабный характер и вызвать необратимые климатические изменения. Обнаружение газовых факелов в водной толще может являться первым признаком наличия газовых гидратов в осадке, поэтому определение количества метана, переносимого газовыми фракелами в воду, мониторинг их временной изменчивости и выявление новых районов газовых фракелов является актуальными задачами современной науки. Результаты проведенного исследования крайне важны для понимания процессов разгрузки пузырькового метана из шельфра-материкового склона Арктических и Субарктических морей. Цель: выполнить оценку количества метана, переносимого газовыми факелами с глубины 2220 м в воду, в период с 2012 по 2018 ге.; выявить связь между потоком метана из данной области и глубинными землетрясениями, произошедшими в Охотском море; по имеющимся акустическим данным оценить скорости глубоководных течений в районе обнаружения ГФ.

Объекты: газовые факелы.

Методы. Акустические наблюдения за газовыми фракелами проводились с помощью комплекса, установленного на борту НИС «Академик М.А. Лаврентьев», основу которого составляют модернизированные судовые эхолоты Сарган-ЭМ, ELAC LAZ-72, гидролокаторы Сарган-ГМ и многоканальная система цифровой регистрации акустических сигналов. Оценка потока метана в воду проводилась с помощью методов, основанных на измерении профиля сечения обратного рассеяния звука на частотах выше резонансной частоты пузырьков, формирующих ГФ.

Результаты. В ходе 15 экспедиций в Охотском море в интервале глубин от 46 до 3330 м было зарегистрировано 1168 индивидуальных газовых факела. Для выявления закономерностей пространственного распределения газовых фракелов был построен графрик зависимости их числа от глубины их обнаружения. На полученном графиие выделяются пять локальных максимумов, приуроченных к особенностям рельефа и зоне стабильности газогидрата метана. Наиболее глубоководные из известных газовых факелов обнаружены в Охотском море на северном и восточном склонах Курильской котловины на глубинах 3330 и 2220 м соответственно. Данные газовые факелы отличались сильной временной изменчивостью, приуроченной к тектонической активности в данном регионе. В работе показано, что поток метана, выделяемого одним из газовых факелов, изменялся на три порядка в диапазоне от 5 ммоль/с до 5 моль/с. Основываясь на имеющихся акустических данных, была рассчитана скорость глубоководного течения в Курильской котловине в интервале глубин от 1100 до 2200 м, которая составила 7 см/с.

Ключевые слова:

Охотское море, акустические исследования, газовые фракелы, метан, глубоководные течения, поток метана в воду. 


\section{Введение}

Газовые факелы (ГФ) - области пузырьковой эманации природных газов из морского дна в водную толщу и атмосферу - обнаружены повсеместно на глубинах от нескольких метров до 2 и более километров (рис. 1, a) [1-10]. Прямые измерения проб газа, переносимого всплывающими пузырьками, показали, что в их составе содержится более 80 \% второго по значимости парникового газа - метана $\left(\mathrm{CH}_{4}\right)$, эмиссии которого за счет расконсервирования депозитов природных углеводородов (например, арктических или океанических газовых гидратов) могут приобрести широкомасштабный характер и вызвать необратимые климатические изменения [11-13].
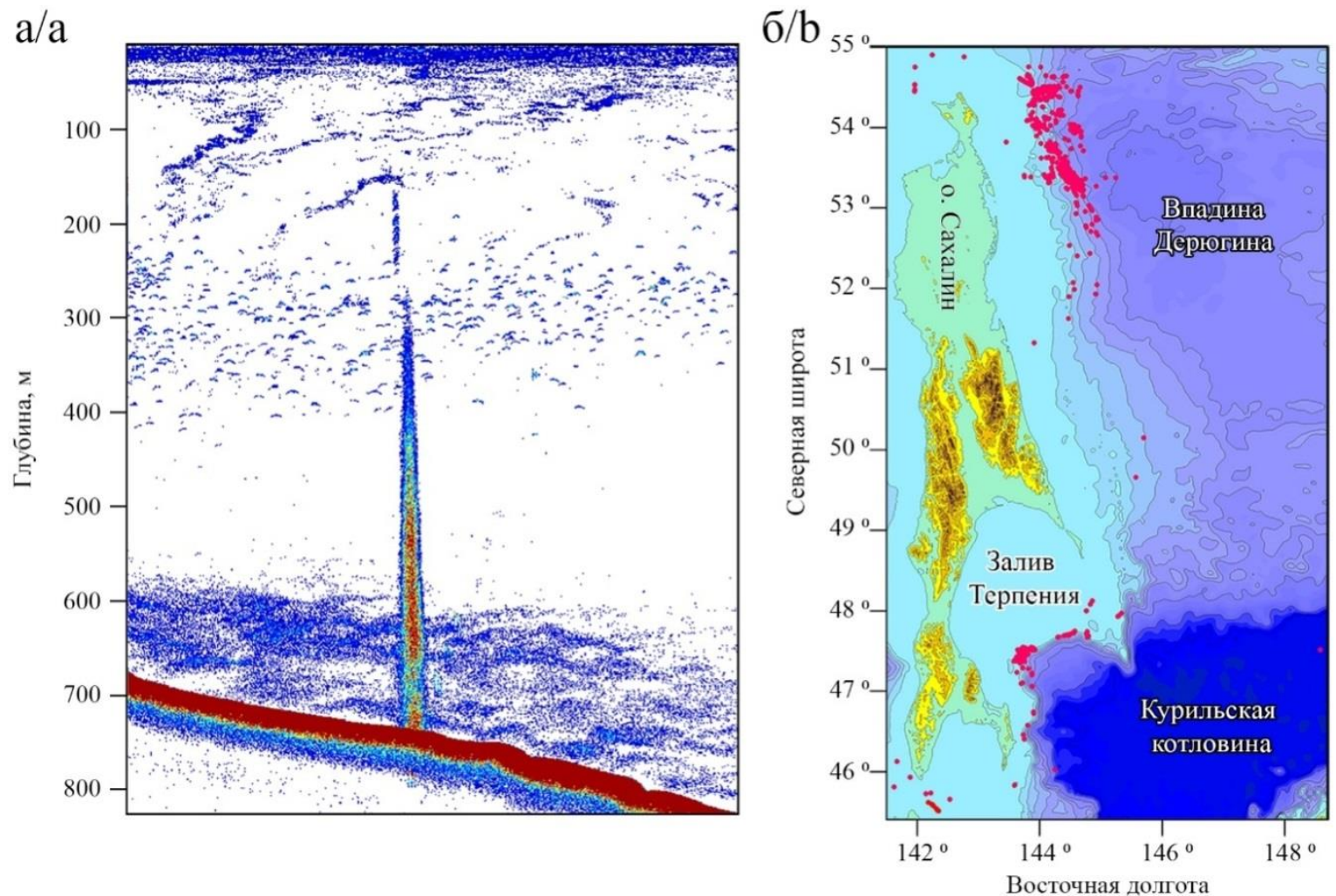

Рис. 1. Пример эхограммы газового факела (а); карта-схема положения газовых факелов, обнаруженных в Охотском море (красные точки)

Fig. 1. Example of gas flare echogram (a); map of the position of seeps detected in the Sea of Okhotsk (red dots)

$\mathrm{CH}_{4}$ является вторым по значимости парниковым газом, содержание которого в атмосфере Земли неуклонно растет [14]. Возрастающий интерес к изучению данного компонента атмосферы объясняется тем, что радиационная активность $\mathrm{CH}_{4}$ значительно выше, а темпы увеличения его концентрации в атмосфере примерно в 2-4 раза быстрее, чем у двуокиси углерода $\left(\mathrm{CO}_{2}\right)$ [15]. Последняя оценка вклада $\mathrm{CH}_{4}$ в современный потенциал глобального потепления, рассчитанная для ближайших 100 лет, показала, что ранние оценки недоучитывали климатическую роль $\mathrm{CH}_{4}$ примерно на 20-40 \% [16-18]. Это значит, что суммарный радиационный форсинг от 1 кг $\mathrm{CH}_{4}$ превышает аналогичную величину для $\mathrm{CO}_{2}$ примерно в 35 раз, а не в 25, как было принято считать до недавнего времени [11]. Согласно палеоклиматическим данным, в результате роста температуры, сопровождающего смену климатических эпох, эмиссия $\mathrm{CH}_{4}$ и, соответственно, атмосферные концентрации увеличиваются примерно в 2 раза: от 0,3-0,4 ppm (холодные эпохи) до 0,6-0,7 ppm (теплые эпохи) [16].

Охотское море - одно из наиболее изученных субарктических морей, в котором на сегодняшний день известно более 1000 ГФ, обнаруженных на глубинах от 40 до 3330 м (рис. 1, б). Акустические исследования ГФ в Охотском море начались в 1982 г. с обнаружения научно-исследовательским судном (НИС) «Геофизик» на глубине 800 м первого ГФ [10]. В настоящее время для поиска и оценки пространственно-временной и временной изменчивости ГФ используются как однолучевые [2, 4, 19-23], так и многолучевые эхолоты [19, 24-26], способные зарегистрировать одиночный всплывающий пузырек на глубинах до 3000 м [27]. ГФ, обнаруженные в Охотском море, приурочены к районам, содержащим в осадочном слое соединения клатратного типа - океанические газовые гидраты, рассматриваемые как потенциальный резерв углеводородного сырья [1, 20, 28, 29].

На сегодняшний день в Охотском море известно два района присутствия газогидратов в донных отложениях: северо-восточная часть континентального склона о. Сахалин (западный борт впадины Дерюгина) и Припарамуширский район Курильских островов (юго-восточный борт Голыгинского прогиба). Газовые гидраты в Охотском море выявлены на небольших поддонных глубинах, на северо-восточном саха- 
линском склоне они отмечаются с поверхности морского дна $[1,28-30]$. Как известно, присутствие газа в гидратном состоянии в непосредственной близости от морского дна возможно только при условии его постоянного поступления снизу $[1,31,32]$. Глубина в районе полей газогидратов, вблизи о. Сахалин и о. Парамушир, составляет от 385 до 1040 м, а температура у дна - в интервалах $2,2-2,3$ и $1,7-2,2{ }^{\circ} \mathrm{C}$, соответственно [20]. Зона стабильности газогидратов метана при таких термобарических условиях может простираться до поддонных глубин не менее 100 м [20]. Установлено, что большинство активных ГФ, связанных с областями скоплений газовых гидратов, сосредоточены в основном в зонах, подверженных процессам тектонического сжатия. ГФ Охотского моря чаще всего встречаются в областях глубокого пригибания, в окраинных бассейнах и перед дугами в 30нах субдукции [33].

В основу данной работы легли результаты исследований, полученные в 15 морских экспедициях в
Охотское море на НИС «Академик М.А. Лаврентьев» с 2002 по 2018 гг. В работе представлены два самых глубоководных из известных ГФ, обнаруженные на глубине 3330 и 2220 м. Для ГФ, обнаруженного на глубине 2220 м, дана оценка потока метана, транспортированного им в воду, а также выявлена связь между потоком метана из данной области и глубинными землетрясениями, произошедшими в Охотском море. Благодаря многократной регистрации данного ГФ с высокой точностью была определена скорость глубоководного течения в данном районе.

\section{Аппаратура и методика}

Акустические наблюдения проводились с помощью комплекса, установленного на борту НИС «Академик М.А. Лаврентьев», основу которого составляют модернизированные судовые эхолоты Сарган-ЭМ, ELAC LAZ-72, гидролокаторы Сарган-ГМ и многоканальная система цифровой регистрации акустических сигналов (рис. 2).
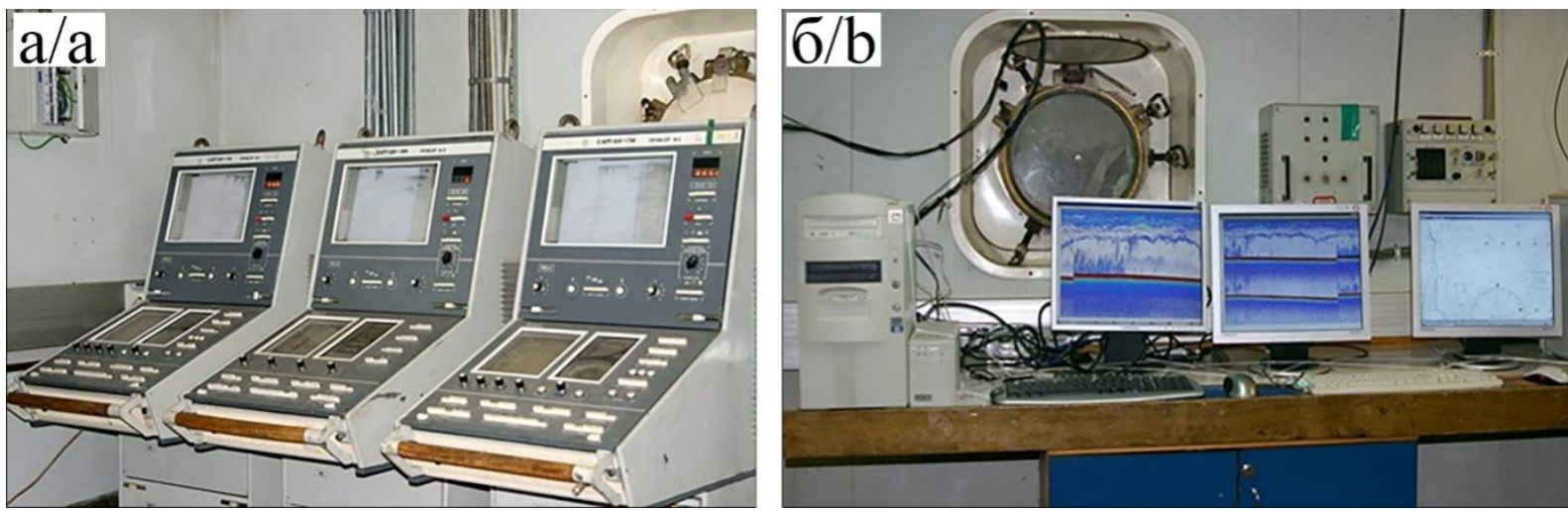

Рис. 2. Эхолот Сарган ЭМ и гидролокаторы Сарган-ГМ (а); многоканальная система цифровой регистрации акустических сигналов (б)

Fig. 2. Echosounder Sargan-EM and hydrolocators Sargan-GM (a); multichannel system of digital acoustic signals storage and recording $(b)$

Данный комплекс позволяет проводить одновременную регистрацию акустических сигналов по четырем независимым каналам на частотах 12, 20 (два канала) и 135 кГц. Одновременно с акустическими данными запи- сываются точные координаты судна, полученные с помощью системы глобального позиционирования (GPS). Блок-схема комплекса представлена на рис. 3, a. В таблице приведены его основные параметры. $\mathrm{a} / \mathrm{a}$

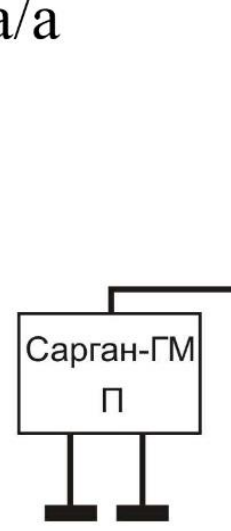

$20 \quad 135$

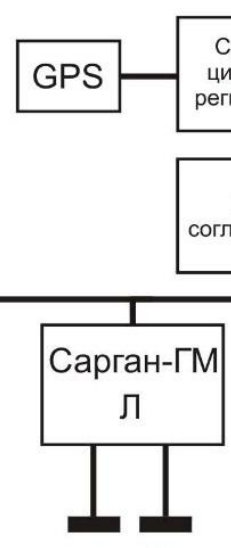

$20 \quad 135$
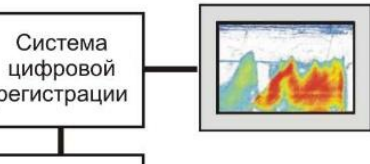

\section{Блок} согласования

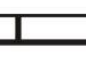

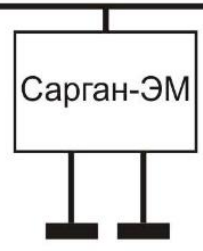

$20 \quad 135$

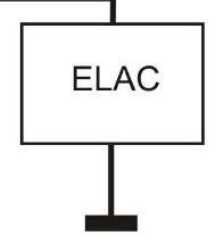

12
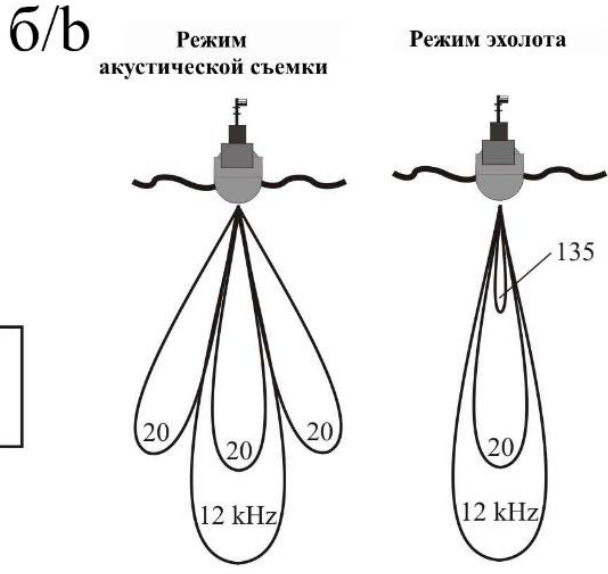

Pис. 3 Блок-схема акустического комплекса (a) и его конфигурачия в разных режсимах (б)

Fig. 3. Flow chart of acoustic complex (a) and its configuration in different modes (b) 
Таблица. Основные характеристики гидролокаторов Table. Basic characteristics of sonar

\begin{tabular}{|c|c|c|c|c|}
\hline $\begin{array}{c}\text { Название } \\
\text { эхолота } \\
\text { Echosounder name }\end{array}$ & ELAC & $\begin{array}{l}\text { Сарган-ЭМ } \\
\text { Sargan-EM }\end{array}$ & \multicolumn{2}{|c|}{$\begin{array}{l}\text { Сарган-ГМ } \\
\text { Sargan-GM }\end{array}$} \\
\hline $\begin{array}{l}\text { Рабочая частота, кГц } \\
\text { Frequency, } \mathrm{kHz}\end{array}$ & 12,0 & 19,7 & 19,7 & 135,0 \\
\hline 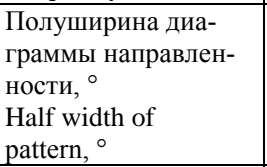 & 6,0 & 5,0 & 7,0 & 2,0 \\
\hline $\begin{array}{l}\text { Импульсная мощ- } \\
\text { ность, кBт } \\
\text { Power, kW }\end{array}$ & 2,0 & 6,0 & 2,5 & 2,0 \\
\hline $\begin{array}{l}\text { Длительность зон- } \\
\text { дирующих импуль- } \\
\text { сов, мс } \\
\text { Impulse length, ms }\end{array}$ & $\begin{array}{c}0,8 ; 3,0 \\
10,0\end{array}$ & $\begin{array}{c}0,5 ; 1,0 ; 3,0 ; \\
10,0\end{array}$ & $\begin{array}{l}1,0 ; 3,0 \\
10,0 \\
30,0\end{array}$ & $\begin{array}{c}0,16 \\
0,3 ; 1,0 \\
3,0\end{array}$ \\
\hline
\end{tabular}

Гидроакустический комплекс позволяет проводить сбор акустической информации в двух основных режимах - походном и исследовательском. На полном ходу судна (9-12 узлов) применяется походный режим. Акустическое зондирование проводится в вертикальном направлении. Сбор информации происходит на частотах 12, 20 и 135 кГц на трех независимых каналах (рис. 3, б). В заданных районах работ (полигонах) на малом ходу судна (3-6 узлов) применяется исследовательский режим. Эхолоты ELAC и СарганЭМ (частоты 12 и 20 кГц) зондируют в вертикальном направлении, а гидролокаторы Сарган-ГМ (частота 20 кГц) наклонены под углами $30^{\circ}$ к морскому дну в разные стороны (рис. 3, б). Подобная конфигурация акустического комплекса позволяет увеличить в три раза исследуемую площадь и получить наиболее детальную информацию об акустических неоднородностях в водном столбе и свойствах дна.

Сбор, первичная обработка и визуализация накопленной акустической информации осуществлялась с помощью многоканальной системы цифровой регистрации данных (рис. 2, б). Акустический аналоговый сигнал с помощью аналогово-цифрового преобразователя конвертируется в цифровой, далее проводится его синхронное детектирование и низкочастотная фильтрация. Визуализация собранных в реальном масштабе времени данных осуществляется в виде цветных эхограмм (рис. 4), причем каждый канал может отображаться одновременно на нескольких эхограммах с независимыми параметрами глубин и цветовой палитрой.

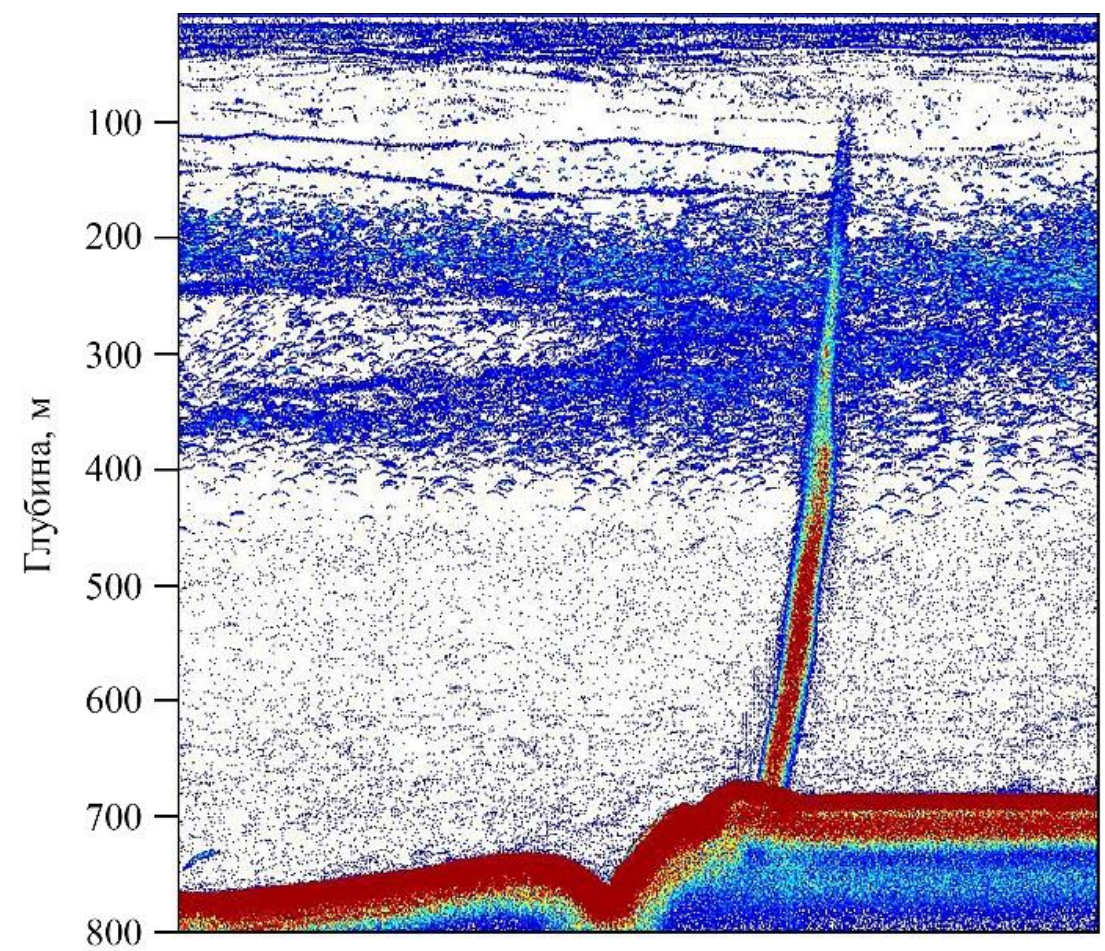

Pис. 4 Пример отображения эхограмм программой «Sопіс» в режиме акустической съемки

Fig. 4. Example of display of echograms by the Sonic program in acoustic mapping

Разработанный комплекс позволяет проводить поиск и исследование ГФ и их источников, а также выделять особенности акустического рассеяния в верхней осадочной толще. Для получения количественной оценки потока метана, переносимого ГФ в воду, данный комплекс был откалиброван по методу кратных отражений акустического сигнала от морского дна [34]. В отличие от калибровки с помощью эталонной цели $[19,35]$, такая калибровка выполняется одним человеком, не требует дополнительного оборудования и во многих случаях - дополнительного судового времени. Результатом калибровки являлось определение калибровочного коэффициента, связывающего между собой величину объемного обратного рассеяния с амплитудой полученного акустического сигнала.

ГФ на шельфе Охотского моря были обнаружены на глубинах от 46 до 3300 м (рис. 1, б), большая их часть глубоководные, обнаруженные на глубинах 200 и более 
метров [8]. Вид таких ГФ на эхограмме определяется профилем течения, направлением движения судна и точностью, с которой судно прошло над источником ГФ. Для иллюстрации наиболее распространенных вариантов отображения глубоководных ГФ на эхограмме воспользуемся следующей эхолокационной моделью:

- Научно-исследовательское судно в момент регистрации ГФ должно двигаться с постоянной скоростью.

- Источники пузырьков на морском дне должны быть точечными (много меньше размера озвученной эхолотом зоны).

- ГФ должны иметь ярко выраженные границы, например, как на рис. 5, $a$.
- Скорость всплытия пузырьков $\left(V_{\mathrm{B}}\right)$ в ГФ должна быть постоянной.

- Скорость течения $V_{\mathrm{T}}$ и его направление постоянные.

- Акустическое зондирование должно производится в вертикальном направлении.

В таком случае всплывающие пузырьки выстраиваются в линию с углом наклона $\alpha$, который вычисляется по формуле:

$$
\alpha=\operatorname{arctg}\left(V_{\mathrm{T}} / V_{\mathrm{B}}\right) .
$$

На рис. 5, б приведены рассчитанные по данной модели варианты отображения ГФ, обнаруженного на глубине 1000 м, при различных значениях угла пересечение ГФ с курсом судна и направлением течения $\gamma$. $\mathrm{a} / \mathrm{a}$

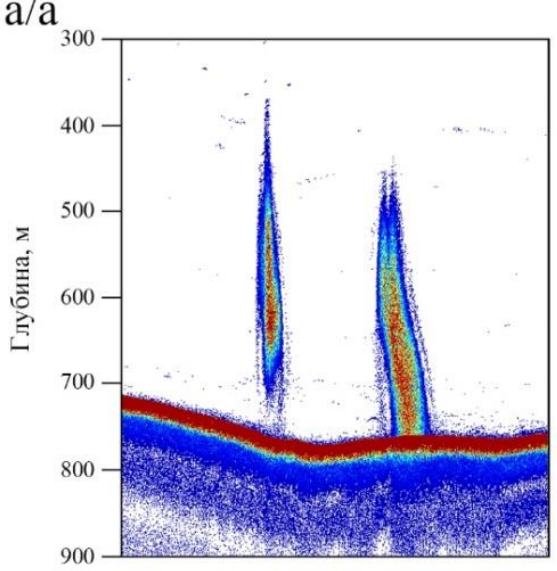

$\sigma / b$

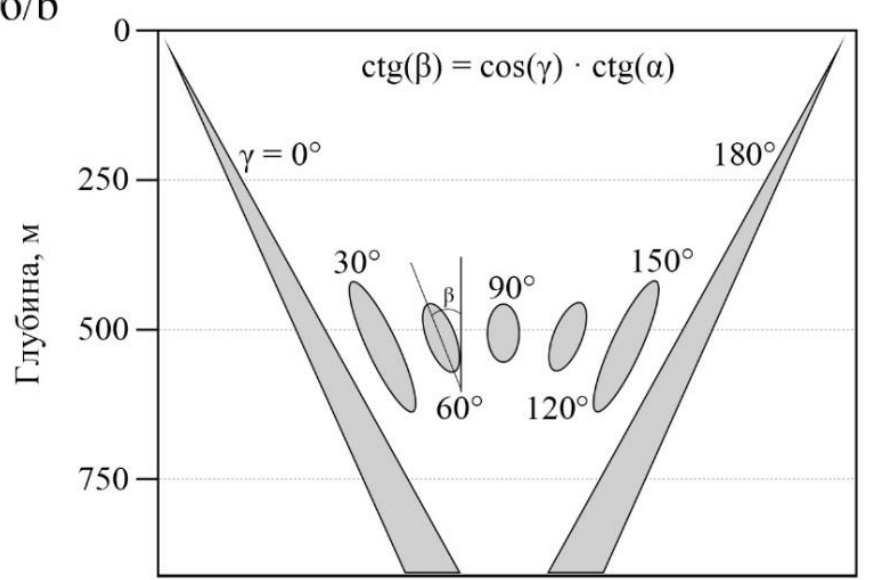

Рис. 5. Пример эхограммы газовых факелов, удовлетворяющих эхолокационной модели (а); модель отображение газового факела на эхограмме при его пересечении под разными углами к курсу судна и направлению течения $\gamma$ (б)

Fig. 5. Example of gas flares echogram satisfying the echolocation model (a); the model displays the gas flare on the echogram when it intersects at different angles to the heading of the vessel and the direction of the current $\gamma(b)$

Из рис. 5, б следует, что форма ГФ на эхограмме существенным образом зависит от угла $\gamma$. Видимый угол наклона $\beta$ оси ГФ изменяется от $\alpha$ при движении судна вдоль факела до нуля при движении поперек его. Данная зависимость описывается выражением:

$$
\operatorname{ctg}(\beta)=\cos (\gamma) \cdot \operatorname{ctg}(\alpha) \text {. }
$$

В случае движения судна вдоль течения ( $\gamma=0$ или $\gamma=180)$ ГФ прослеживается от морского дна до своей верхней точки, а видимый на эхограмме поперечный размер ГФ постепенно уменьшается от дна к поверхности. Такой случай дает полное представление о высоте ГФ и его внутренней структуре. Координаты ГФ с высокой точностью совпадают с координатами судна в момент обнаружения ГФ. Возможная ошибка в нахождении координат ГФ в основном определяется полушириной диаграммы направленности эхолота и глубиной. При движении судна вдоль течения видимый угол наклона оси ГФ $\beta$ (рис. $5, \sigma)$ совпадает с реальным углом наклона ГФ $\alpha$, что при известной скорости всплытия пузырьков позволяет определить скорость течения с помощью выражения (1).

При движении судна под прямым углом к течению $(\gamma=0)$ на эхограмме отображается только минимальная часть ГФ (рис. 5, б), глубина которой зависит от отношения скорости течения к скорости всплытия пу- зырьков и расстояния между линией движения судна на дне и источником ГФ. Если ГФ не прослеживался до дна (рис. 6), то за координаты источника ГФ принимались координаты судна в момент пересечения ГФ. В этом случае возможная ошибка в нахождении координат ГФ увеличивается на расстояние между зарегистрированным ГФ и дном, умноженным на отношение скоростей течения и всплытия пузырьков.

Воспользовавшись выражением (1), рассчитаем реальный угол наклона ГФ и оценим расстояние от НИС до источника данного ГФ на морском дне. Ширина данного ГФ составляет 160 м и хорошо совпадает с рассчитанной по акустической модели шириной ГФ, зарегистрированного в водной толще (рис. 5, б). Видимый на эхограмме угол наклона ГФ $\beta \approx 15^{\circ}$, а угол между курсом судна и течением $\gamma \approx 45^{\circ}$. Реальный угол наклона ГФ $(\alpha)$ в интервале глубин 400-800 м, рассчитанный с помощью выражения (2), составляет $20^{\circ}$. Полагая, что скорость всплытия пузырьков $18 \mathrm{~cm} / \mathrm{c}$ [8], с помощью выражения (1) получим значение средней скорости течения в интервале глубин 400-800 м, равное 7 см/с. Если предположить, что глубоководное течение в данном районе Курильской котловины постоянно, то источник ГФ на морском дне находится на удалении в 800 м от места его регистрации в водном столбе. 

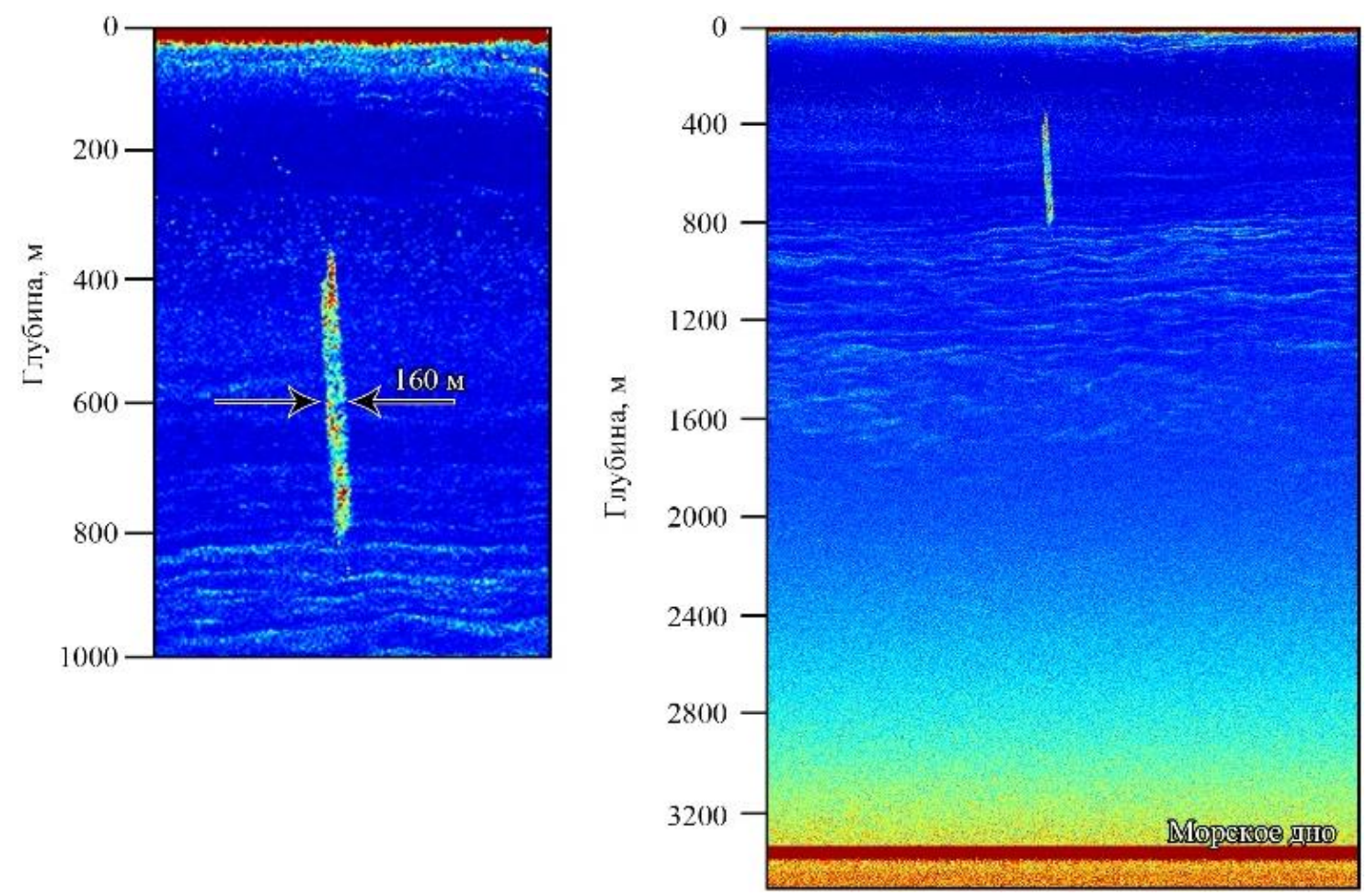

Pис. 6. Пример глубоководного газового факела (глубина дна 3330 м), зарегистрированного в водной толще под углом к течению $\gamma=45^{\circ}$

Fig. 6. Sample of deep-sea gas flare (bottom depth $3330 \mathrm{~m}$ ) at right angles to the current $\gamma=45^{\circ}$

\section{Результаты}

В 15 экспедициях на НИС «Академик М.А. Лаврентьев» в Охотском море было выполнено 1500 регистраций ГФ в интервале глубин от 46 до 3330 м (рис. 1, б). В том числе 116 ГФ были зарегистрированы многократно. Большинство обнаруженных ГФ (1168 ед.) расположено у северной оконечности о. Сахалин в интервале широт 52-55 с.ш., 957 из которых находятся в районе Дерюгинского осадочно-породного бассейна (рис. 1, б). Оставшиеся ГФ приурочены к южной оконечности о. Сахалин и проливу Лаперуза (рис. 1, б). Для выявления закономерностей пространственного распределения ГФ был построен график зависимости их числа от глубины их обнаружения (рис. 7, a). На полученном графике выделяются пять локальных макси- мумов, первый из которых находится на глубине 175 м. Данный максимум приурочен к бровке континентального шельфа Охотского моря. Второй максимум, глубина 375 м, связан с нижней границей зоны стабильности газогидрата метана, сосредоточенного в осадках $[1,8,20,22,29,30,36]$. Третий находится на глубине 675 м и соответствует зоне перегиба континентального склона (рис. 1, б). Четвертый локальный максимум находится на глубине 975 м, его связь с особенностями рельефа дна или тектоникой плит не выявлена.

Последний из максимумов находится на глубине 1275 м. Из 35 ГФ, обнаруженных в этом интервале глубин, 34 находятся на небольшом участке морского

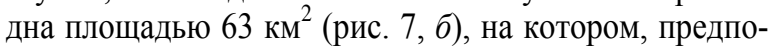
ложительно, находится грязевой вулкан [37].
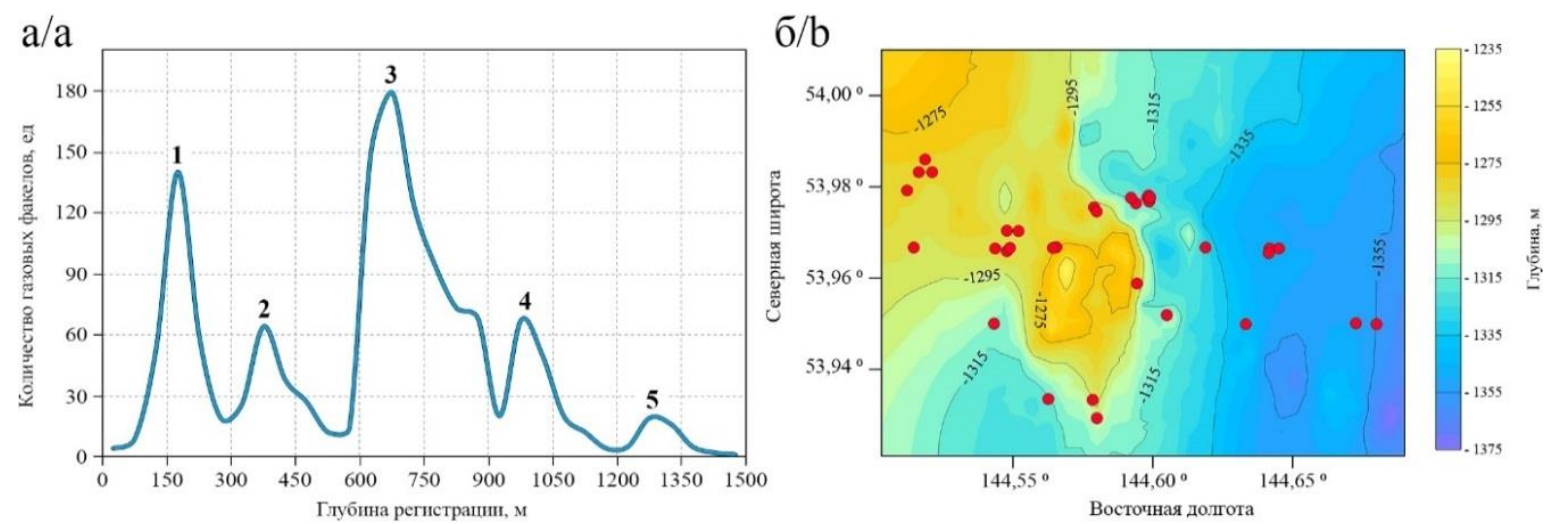

Рис. 7. График зависимости количества газовых факелов от глубины их обнаружения (а); батиметрическая карта предполагаемого грязевого вулкана с обнаруженными в данном районе газовыми факелами (красные точки) (б)

Fig. 7. Chart of the number of gas flares on depth its detections (a); bathymetric map of the supposed mud volcano, with seeps found at the area (red dots) (b) 
Стоит выделить наиболее глубоководные из известных ГФ, обнаруженные в Курильской котловине на глубинах 3330 и 2220 м [38], соответственно. Глубоководный ГФ высотой около трех километров был зарегистрирован один раз на полном ходу судна при переходе между полигонами. Из-за наличия сильного глубоководного течения зарегистрировать удалось только его верхнюю часть (рис. 6). Второй глубоководный ГФ, высотой около двух километров (рис. 8), стабильно регистрировался в течение пяти лет.

Данный ГФ отличался сильной временной изменчивостью, поток метана, выделяемого им, менялся в диапазоне от 5 ммоль/с до 5 моль/с. Оценка потока метана в воду проводилась с помощью методов, основан- ных на измерении профиля сечения обратного рассеяния звука на частотах выше резонансной частоты пузырьков, формирующих ГФ $[8,22]$. При первой регистрации данного ГФ поток метана составил 50 ммоль/с (F1, рис. 8). При повторной регистрации (F2-F4, рис. 8), через пять часов после землетрясения магнитудой (Mw) 7,7 баллов, произошедшего северо-восточнее Поронайска [39], поток метана из данного ГФ возрос на 2 порядка и достиг 5 моль/с. Следует отметить, что сразу после глубокофокусного землетрясения поток выходящих пузырьков, формирующих данный ГФ, имел сильные пульсации с периодом 3,5 минуты. Подобные пульсации, со схожим периодом, наблюдались ранее у другого ГФ, обнаруженного на глубине 700 м [8].

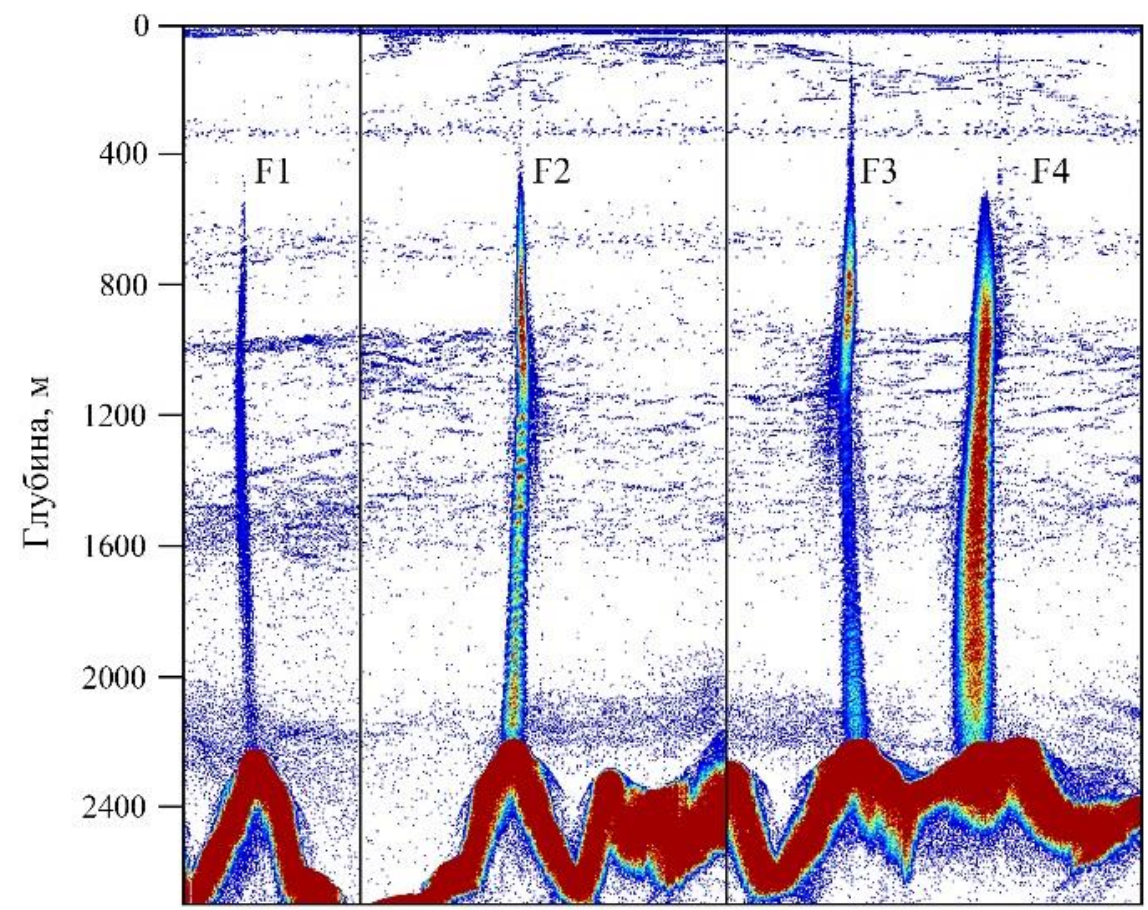

Рис. 8. Эхограммы глубоководного газового факела до (F1) и после землетрясения магнитудой 7,7 баллов (F2-F4)

Fig. 8. Echograms of deep-sea gas flare till (F1) and after earthquakes of 7,7 points magnitude (F2-F4)

Наблюдения за данным ГФ в период с 2013 по 2016 гг. повторялись еще три раза. В 2013 г. регистрация ГФ была выполнена через 30 суток после глубокофокусного землетрясения с $\mathrm{Mw}=8,3$ баллов и эпицентром, находящимся в Охотском море на глубине 630 км $[39,40]$. Средний поток из данного ГФ в момент регистрации составил 1 моль/с. В 2014 и в 2016 гг. поток из данного ГФ ослаб на 3 порядка и составил около 5 ммоль/с.

Отметим, что на существование связи между рельефом, глубинами дна и расположением ГФ ранее обращалось внимание в работе [8], а отдельные наблюдения за месторасположением ГФ приведены в $[41,42]$. В морях Восточной Арктики также были выявлены районы массированной разгрузки метана, которые были ассоциированы с районами высокой сейсмотектонической активности и аномально высокого геотермического потока тепла, который усиливает деградацию подводной мерзлоты и дестабилизацию гидратов снизу [11, 43-46].

\section{Выводы}

В 15 экспедициях на научно-исследовательском судне «Академик М.А. Лаврентьев» в Охотском море у берегов о. Сахалин в интервале глубин от 46 до 3330 м было зарегистрировано 1168 индивидуальных ГФ. Для выявления закономерностей пространственного распределения ГФ был построен график зависимости их числа от глубины их обнаружения (рис. 7, a). На полученном графике выделяются пять локальных максимумов, приуроченных к особенностям рельефа и зоне стабильности газогидрата метана.

Наиболее глубоководные ГФ обнаружены в Охотском море на северном и восточном склонах Курильской котловины на глубинах 3330 и 2220 м соответственно. Данные ГФ отличаются сильной временной изменчивостью, приуроченной к тектонической активности данного региона, вызывающей изменение интенсивности переносимого ими метана в виде всплывающих пузырьков. В работе показано, что поток метана, выделяемого одним из таких ГФ, изме- 
нялся на три порядка в диапазоне от 5 ммоль/с до 5 моль/с. Более высокая пространственно-временная изменчивость потоков пузырькового метана из донных отложений в водную толщу была документирована только на шельфе морей Восточной Арктики, где дестабилизация гидратов связана с темпами и масштабами деградации подводной мерзлоты.

Данная работа является первым шагом в понимании причинно-следственных связей между разгрузкой метана в различных частях мега-разлома между Евразийской и Северо-Американской тектоническими плитами: в глубоководном Охотском море и мелководном шельфе морей Восточной Арктики.

\section{СПИСОК ЛИТЕРАТУРЫ}

1. Conditions of gas hydrate formation in the Sea of Okhotsk / V.A. Akulichev, A.I. Obzhirov, R.B. Shakirov, E.V. Maltseva, A.I. Gresov, Y.A. Telegin // Doklady Earth Sciences. - 2014 . V. 454. - № 1. - P. 94-96.

2. Massive blow-out craters formed by hydrate-controlled methane expulsion from the Arctic seafloor / K. Andreassen, A. Hubbard, M. Winsborrow, H. Patton, S. Vadakkepuliyambatta, A. PlazaFaverola, E. Gudlaugsson, P. Serov, A. Deryabin, R. Mattingsdal, J. Mienert, S. Bunz // Science. - 2017. - V. 356. - № 6341. - P. 948-952.

3. 1300-m-high rising bubbles from mud volcanoes at $2080 \mathrm{~m}$ in the Black Sea: Hydroacoustic characteristics and temporal variability / J. Greinert, Y. Artemov, V. Egorov, M. De Batist, D. McGinnis // Earth and Planetary Science Letters. - 2006. - V. 244. - № 1-2. - P. 1-15.

4. Methane seeps at the Hikurangi Margin, New Zealand / J. Greinert, J. Bialas, K. Lewis, E. Suess // Marine Geology. - 2010. V. 272. - № 1-4. - P. 1-3

5. Effects of climate change on methane emissions from seafloor sediments in the Arctic Ocean: a review / R.H. James, P. Bousquet, I. Bussmann, M. Haeckel, R. Kipfer, I. Leifer, H. Niemann, I. Ostrovsky, J. Piskozub, G. Rehder, T. Treude, L. Vielstadte, J. Greinert // Limnology and Oceanography. - 2016. - V. 61. - P. S283-S299.

6. Leifer I., Patro R.K. The bubble mechanism for methane transport from the shallow sea bed to the surface: a review and sensitivity study / Continental Shelf Research. - 2002. - V. 22. - № 16. - P. 2409-2428.

7. A study of the gas seep Istok in the Selenga shoal using active acoustic, passive acoustic and optical methods / M. Makarov, S. Muyakshin, K. Kucher, I. Aslamov, N. Granin // Journal of Great Lakes Research. - 2020. - V. 46. - P. 95-101

8. Salomatin A.S., Yusupov V.I. Acoustic Investigations of Gas «Flares» in the Sea of Okhotsk // Oceanology. - 2011. - V. 51. № 5. - P. 857-865.

9. Methane transport and sources in an Arctic deep-water cold seep offshore NW Svalbard (Vestnesa Ridge, $79^{\circ} \mathrm{N}$ ) / S. Sauer W.-L. Hong, H. Yao, A. Lepland, M. Klug, F. Eichinger, T. Himmler, A. Crémière, G. Panieri, C. J. Schubert, J. Knies // Deep Sea Research Part I: Oceanographic Research Papers. 2021. - V. 167. - P. 103430

10. Авдейко Г.П., Гавриленко Г.М., Черткова Л.В «Вулканолог» исследует подводный факел (О геологических изысканиях научно-исследовательского судна в Тихом океане) // Природа. -1986 . - Т. 7. - С. $80-87$.

11. Shakhova N., Semiletov I., Chuvilin E. Understanding the Permafrost-Hydrate System and Associated Methane Releases in the East Siberian Arctic Shelf// Geosciences. - 2019. - V. 9. - P. 1-23.

12. Hovland M., Judd A., Burke R. The global flux of methane from shallow submarine sediments // Chemosphere - 1993 - V. 26. - P. 559-578.

13. Evidence of Gas Emissions from Permafrost in the Russian Arctic/ E. Chuvilin, V. Ekimova, D. Davletshina, N. Sokolova, B. Bukhanov // Geosciences. - 2020. - V. 10. - № 10. URL https://www.researchgate.net/publication/344363803_Evidence_of Gas_Emissions_from_Permafrost in the Russian Arctic (дата обращения 26.07.2021).

14. Statistical estimation of global surface temperature response to forcing under the assumption of temporal scaling / E. MyrvollNilsen, S.H. Sørbye, H.B. Fredriksen, H. Rue, M. Rypdal // Earth Syst. Dynam. - 2020. - V. 11. - № 2. - P. 329-345.
Авторы работы выражают благодарности экипажу НИС «Академик М.А. Лаврентьев». Частично данная работа была выполнена в рамках государственных заданий № AAAA-A20-120021990003-3 (АС, ДВ), 121021500057-4 (ОД, ИС и ДК.), 0128-2021-0005 (РА) и грантов Президента РФ для государственной поддержки молодых российских ученых - кандидатов наук МК-3476.2021.1.5 (ЕГ) и МК-535.2020.5 (АГ). Исследования, выполненные в контексте фундаментального понимания изменения климатических процессов, происходящих в арктических и субарктических морях, были выполнены в рамках гранта РНФ № 21-7730001 (ИС). Отдельные аспекты работы были выполнены в рамках гранта Минобрнауки (№ соглашения о предоставлении гранта: 075-15-2020-978 НШ).

15. IPCC, 2001: climate change 2001: impacts, adaptation and vulnerability. Contribution of Working Group II to the Third Assessment Report of the Intergovernmental Panel on Climate Change / J.E. Thornes, J.J. McCarthy, O.F. Canziani, N.A. Leary, D.J. Dokken, K.S. White // International Journal of Climatology. 2002. - V. 22. - № 10. - P. 1285-1286.

16. Climate change 2007: the physical science basis. Contribution of Working Group I to the Fourth Assessment Report of the Intergovernmental Panel on Climate Change. - Cambridge; New York: Cambridge University Press, 2007. URL: https://www.ipcc.ch/report/ar4/wg1/ (дата обращения 26.07.2021).

17. Renewable energy sources and climate change mitigation: special report of the intergovernmental panel on climate change / O. Edenhofer, R.P. Madruga, Y. Sokona, K. Seyboth, P. Matschoss, S. Kadner, T. Zwickel, P. Eickemeier, G. Hansen, S. Schlömer, C. Stechow // Renewable Energy Sources and Climate Change Mitigation: Special Report of the Intergovernmental Panel on Climate Change. - 2011. - 1075 p. URL: https://www.ipcc.ch/report/renewable-energy-sources-andclimate-change-mitigation/ (дата обращения 26.07.2021).

18. Improved attribution of climate forcing to emissions / D. Shindell, G. Faluvegi, D. Koch, G. Schmidt, N. Unger, S. Bauer // Science. - 2009. - V. 326. - P. 716-718

19. Sonar estimation of methane bubble flux from thawing subsea permafrost: A case study from the Laptev sea shelf / D. Chernykh, V. Yusupov, A. Salomatin, D. Kosmach, N. Shakhova, E. Gershelis, A. Konstantinov, A. Grinko, E. Chuvilin, O. Dudarev, A. Koshurnikov, I. Semiletov // Geosciences. - 2020. - V. 10. № 10. - P. 1-14.

20. Gas hydrates from the continental slope, offshore Sakhalin Island, Okhotsk Sea / G.D. Ginsburg, V.A. Soloviev, R.E. Cranston, T.D. Lorenson, K.A. Kvenvolden // Geo-Marine Letters. - 1993. V. 13 - № 1. - P. 41-48.

21. Estimation of methane fluxes from bottom sediments of Lake Baikal / N. Granin, S. Muyakshin, M. Makarov, K. Kucher, I. Aslamov, L. Granina, I. Mizandrontsev // Geo-Marine Letters. 2012. - V. 32. - P. 427-436.

22. An acoustic estimate of methane concentration in a water column in regions of methane bubble release / A. S. Salomatin, V.I. Yusupov, O.F. Vereshchagina, D.V. Chernykh // Acoustical Physics. - 2014. - V. 60. - № 6. - P. 671-677.

23. A new methodology for quantifying bubble flow rates in deep water using splitbeam echosounders: Examples from the Arctic offshore NW-Svalbard / M. Veloso, J. Greinert, Mienert J., De Batist M. // Limnology and Oceanography-Methods. - 2015. V. 13. - № 6. - P. 267-287.

24. Sonar gas flux estimation by bubble insonification: application to methane bubble flux from seep areas in the outer Laptev Sea / I. Leifer, D. Chernykh, N. Shakhova, I. Semiletov // Cryosphere. 2017 - V. 11 - № 3 - P. 1333-1350.

25. Improved detection and mapping of deepwater hydrocarbon seeps: optimizing multibeam echosounder seafloor backscatter acquisition and processing techniques / G.A. Mitchell, D.L. Orange, J.J. Gharib, P. Kennedy // Marine Geophysical Research. - 2018. - V. 39. - № 1-2. - P. 323-347.

26. Urban P., Köser K., Greinert J. Processing of multibeam water column image data for automated bubble/seep detection and 
repeated mapping // Limnology and Oceanography: Methods. 2017. - V. 15. - № 1. - P. 1-21.

27. Amount and fate of gas and oil discharged at $3400 \mathrm{~m}$ water depth from a natural seep site in the Southern Gulf of Mexico / M. Römer, C.-W. Hsu, M. Loher, I. Macdonald, C. Ferreira, T. Pape, S. Mau, G. Bohrmann, H. Sahling // Frontiers in Marine Science. - 2019. - V. 6. URL: https://www.researchgate.net/ publication/337300257_Amount and Fate of_Gas_and_Oil_Disc harged_at_3400_m_Water_Depth_From_a_Natural_Seep_Site_in the_Southern_Gulf_of_Mexico (дата обращения 26.07.2021).

28. Kasatkin S.A., Obzhirov A.I. Fluid-controlling significance of the Nosappu fracture zone and conditions for the formation of methane fluxes and gas hydrates (Sea of Okhotsk region) // Russian Journal of Pacific Geology. - 2018. - V. 12. - № 1. - P. 57-62.

29. New data on lineament control of modern centers of methane degassing in East Asian seas / R.B. Shakirov, A.I. Obzhirov, A.S. Salomatin, M.M. Makarov // Doklady Earth Sciences. 2017. - V. 477. - № 1. - P. 1287-1290.

30. The stability of gas hydrate field in the northeastern continental slope of Sakhalin Island, Sea of Okhotsk, as inferred from analysis of hea flow data and its implications for slope failures / Y.G. Kim, S.M. Lee, Y.K Jin., B. Baranov, A. Obzhirov, A. Salomatin, H. Shoji // Marine and Petroleum Geology. - 2013. - V. 45. - P. 198-207.

31. Gas flows in the Sea of Okhotsk resulting from CretaceousCenozoic Tectonomagmatic activity / A.I. Obzhirov, T.A. Emelyanova, Y.A. Telegin, R.B. Shakirov // Russian Journal of Pacific Geology. - 2020. - V. 14. - № 2. - P. 156-168.

32. Matveeva T., Solov'ev V.A. Gas hydrates in Sea of Okhotsk: Regularities in formation and distribution // Lithology and Mineral Resources - 2003. - V. 47. - P. 101-112.

33. Modern biogenic gas-generated craters (sea-floor «pockmarks») on the Bering Shelf, Alaska / N.C. Hans, D.R. Thor, M.W. Sandstrom, K.A. Kvenvolden // GSA Bulletin. - 1979. V. 90. - № 12. - P. 1144-1152.

34. Воловов И.В. Отражение звука от дна океана - М.: Наука, 1993. $-272 \mathrm{c}$.

35. A wideband acoustic method for direct assessment of bubblemediated methane flux / E. Weidner, T.C. Weber, L. Mayer, M. Jakobsson, D. Chernykh, I. Semiletov // Continental Shelf Research. - 2019. - V. 173. - P. 104-115.

36. Forecast of gas hydrates distribution zones in the Arctic Ocean and adjacen offshore areas / V. Bogoyavlensky, A. Kishankov, A. Yanchevskaya, I. Bogoyavlensky // Geosciences. - 2018. - V. 8. - № 12. -P. 1-17.
37. Operation report of Sakhalin slope gas hydrate project 2007, R/V «Akademik M.A. Lavrentyev» Cruise 43. - Kitami, Japan: Kitami Institute of Technology 2008. $-39 \mathrm{p}$.

38. Obzhirov A.I., Sokolova N.L., Telegin Y.A. Geological conditions of the formation and dissociation of gas hydrates in the Sea of Okhotsk: tectonic and genetic aspects // Lithology and mineral resources. - 2021. - V. 56. - № 4. - P. 333-342.

39. The earthquake hazards program website is moving // Docslide. 2021. URL: https://earthquake.usgs.gov (дата обращения 23.02.2021)

40. Глубокое охотоморское землетрясение 24.05 .2013 г. С магнитудой мw=8,3 - сильнейшее сейсмическое событие у берегов Камчатки за период детальных сейсмологических наблюдений / В.Н. Чебров, Ю.А. Кугаенко, С.А. Викулина, Н.М. Кравченко, Е.А. Матвеенко, С.В. Митюшкина, А.А. Раевская, В.А. Салтыков, Д.В. Чебров, А.В. Ландер // Вестник КРАУНЦ. Науки о Земле. - 2013. - Т. 21. - С. 17-24.

41. Kutas R.I., Paliy S.I., Rusakov O.M. Deep faults, heat flow and gas leakage in the northern Black Sea // Geo-Marine Lett. 2004. - V. 24. - P. 163-168.

42. Temporal variations in geophysical fields and earthquake forecasting issues / V.A. Parovyshny, V.N. Senachin, O.V. Veselov, E.V. Kochergin // Geodynamics \& Tectonophysics. - 2015. - V. 6. - № 1. - P. 63-76.

43. Shakhova N.E., Alexeev V.A., Semiletov I.P. Predicted methane emission on the East Siberian Shelf // Doklady Earth Sciences. 2010. - V. 4230 (2). - P. 261-264.

44. Shakhova N.E., Sergienko V.I., Semiletov I.P. The contribution of the East Siberian shelf to the modern methane cycle // Herald of the Russian Academy of Sciences. - 2009. - V. 79. -№ 3. - P. 237-246.

45. Shakhova N.E., Nicolsky D., Semiletov I.P. Current state of subsea permafrost on the East Siberian Shelf: Tests of modeling results based on field observations // Transactions of Russian Academy of Sciences. - 2009. - V. 429 (2) - P. 1518-1521.

46. The East Siberian Arctic Shelf: towards further assessment of permafrost-related methane fluxes and role of sea ice / N. Shakhova, I. Semiletov, V. Sergienko, L. Lobkovsky, V. Yusupov, A. Salyuk, A. Salomatin, D. Chernykh, D. Kosmach, G. Panteleev, D. Nicolsky, V. Samarkin, S. Joye, A. Charkin, O. Dudarev, A. Meluzov, Ö. Gustafsson // Philosophical Transactions Royal Society A. - 2015. - 373. - 20140451.

Поступила 04.08.2021 г.

\section{Информация об авторах}

Черных Д.В., кандидат технических наук, научный сотрудник Лаборатории акустической океанографии Тихоокеанского океанологического института им. В.И. Ильичева.

Саломатин A.C., кандидат физико-математических наук, заведующий Лабораторией акустической океанографии Тихоокеанского океанологического института им. В.И. Ильичева.

Юсупов В.И., кандидат физико-математических наук, научный сотрудник Лаборатории лазерной химии Института фотонных технологий ФНИЦ «Кристаллография и фотоника» РАН.

Шахова H.E., доктор геолого-минералогических наук, профессор, главный научный сотрудник Лаборатории арктических исследований Тихоокеанского океанологического института им. В.И. Ильичева,; главный научный сотрудник Института экологии Высшей школы экономики.

Космач Д.А., научный сотрудник Лаборатории арктических исследований Тихоокеанского океанологического института им. В.И. Ильичева.

Дударев О.В., доктор геолого-минералогических наук, главный научный сотрудник Лаборатории арктических исследований Тихоокеанского океанологического института им. В.И. Ильичева.

Гершелис E.B., кандидат геолого-минералогических наук, доцент отделения геологии, Инженерная школа природных ресурсов Национального исследовательского Томского политехнического университета.

Силионов В.И., ведущий инженер Лаборатории акустической океанографии Тихоокеанского океанологического института им. В.И. Ильичева.

Ананьев P.A., научный сотрудник Лаборатории сейсмостратиграфии Института океанологии им. П.П. Ширшова РАН. Гринько А.А., кандидат химических наук, инженер, Инженерная школа природных ресурсов Национального исследовательского Томского политехнического университета.

Семилетов И.П., член-корреспондент РАН, доктор географических наук, заведующий Лабораторией арктических исследований Тихоокеанского океанологического института им. В.И. Ильичева; научный руководитель Международной научно-образовательной лаборатории изучения углерода арктических морей Национального исследовательского Томского политехнического университета. 
UDC 551.462:551.463:551.464

\section{ACOUSTIC INVESTIGATIONS OF THE DEEPEST METHANE SEEPS IN THE OKHOTSK SEA}

Denis V. Chernykh ${ }^{1}$,

denis.chernykh.vl@gmail.com

\section{Alexander S. Salomatin ${ }^{1}$,} salomatin@poi.dvo.ru

Vladimir I. Yusupov², iouss@yandex.ru

Natalia E. Shakhova1,3, nataliafletcher@yahoo.com

Denis A. Kosmach ${ }^{1}$, den-kosmach@mail.ru

\section{Oleg V. Dudarev'1,} dudarev@poi.dvo.ru

1 Russian Academy of Sciences, Pacific Oceanological Institute, 43, Baltiiskaya street, Vladivostok, 690041.

2 Russian Academy of Sciences Institute of Photon Technologies, Federal Scientific Research Centre "Crystallography and Photonics», 59, Leninskiy avenue, Moscow, 119333, Russia.

3 Higher School of Economics, 20, Myasnitsky street, Moscow, 101100, Russia.

${ }_{4}$ National Research Tomsk Polytechnic University, 30, Lenin avenue, Tomsk, 634050, Russia.

5 Shirshov Institute of Oceanology, Russian Academy of Sciences, 36, Nahimovskiy avenue, Moscow, 117997, Russia.
Elena V. Gershelis 4 ,
elenapanova@tpu.ru

Vyacheslav I. Silionov ${ }^{1}$ truexenox@gmail.com

Roman A. Ananiev 5 , corer@mail.ru

Andrey A. Grinko4, grinko@tpu.ru

Igor P. Semiletov ${ }^{1,4}$, ipsemiletov@gmail.com

The relevance. Seeps - areas of bubble emanation of natural gases from the seabed into the water column and the atmosphere - were found in different World Ocean locations at depths from tens meters to several kilometers. Direct measurements of gas samples carried by rising bubbles have shown that they contain more than $80 \%$ of the second most important greenhouse gas - methane. The emissions of which, due to the re-preservation of deposits of natural hydrocarbons (for example, arctic or oceanic gas hydrates), can acquire a largescale character and cause irreversible climatic changes. Detection of seeps in the water column may be the first indication of the presence of gas hydrates in the sediment. Therefore, assessment of the methane fluxes carried by seeps into the water column, detection of their variability, and identification of new regions of seepage are in the forefront of the marine and climate-related sciences. Moreover, understanding of deep seepage mechanism from disturbed gas hydrates observed in the Sea of Okhotsk is crucially important for study of methane ebullition from the shelf slope hydrates in the East Siberian Arctic seas - source of atmospheric methane of global significance.

The main aim: to assess the quantity of methane transported by methane seeps from a depth of $2220 \mathrm{~m}$ into the water for the period from 2012 to 2018; to identify the relationship between the flux of methane from this area and deep earthquakes that occurred in the Sea of Okhotsk; based on the available acoustic data, estimate the speed of deep-water currents in the seepage areas.

Objects: seeps, which forms hot spots of anomalously high dissolved methane concentrations in the water column-atmosphere.

Methods. Acoustic observations of the seeps were carried out using a complex unit installed on board of the RV "Academic M.A. Lavrentiev", which is based on modernized ship echosounders Sargan-EM, ELAC LAZ-72, Sargan-GM sonars and a multichannel system for digital recording of acoustic signals. Methane flux from the seabed into the water column was estimated using methods based on measuring the profiles of the sound backscattering at frequencies above the resonant frequency of the escaping bubbles.

Results. In 15 expeditions accomplished in the Sea of Okhotsk, 1168 individual seeps were recorded in the depth interval from 46 to $3330 \mathrm{~m}$. To identify the patterns of the spatial distribution of seeps, a graph was plotted as their number vs the depth of their detection. The resulting graph shows five local maximums associated with the features of the bottom relief and the zone of stability of methane gas hydrate. The deepest known seeps in the Sea of Okhotsk were found in the northern and eastern slopes of the Kuril Basin at depths of 3330 and $2220 \mathrm{~m}$, respectively. The seepage data were characterized by strong temporal variability, confined to tectonic activity in this region, causing a change in the intensity of the methane transported by them in the form of rising bubbles. It is shown that the flow of methane released by one of the seeps varied three orders in the range from $5 \mathrm{mmol} / \mathrm{s}$ to $5 \mathrm{~mol} / \mathrm{s}$. Based on the available acoustic data, the speed of the deep-water current in the Kuril Basin, $\sim 7 \mathrm{~cm} / \mathrm{s}$, was calculated in the depth interval from 1100 to $2200 \mathrm{~m}$.

\section{Key words:}

Sea of Okhotsk, deep and shallow Arctic hydrates, acoustic research, seeps, methane, deep-water currents, methane release from sea bottom to water column. 
The authors of the work express their gratitude to the crew of the $R / V$ «Akademik M.A. Lavrentiev». This work was partially carried out within the framework of state assignments no. AAAA-A20-120021990003-3 (AS, DV), 121021500057-4 (OD, IS and DK.), 0128-2021-0005 (RA) and the grants of the President of the Russian Federation for state support of young Russian scientists - candidates of sciences MK-3476.2021.1.5 (EG) and MK-535.2020.5 (AG). The studies were carried out in the context of a fundamental understanding of the changes in climatic processes occurring in the Arctic and subarctic seas within the framework of the Russian Science Foundation grant no. 21-77-30001 (IS). Certain aspects of the work were carried out within the framework of a grant from the Ministry of Education and Science (Grant Agreement No. 075-15-2020-978 NSh).

\section{REFERENCES}

1. Akulichev V.A., Obzhirov A.I., Shakirov R.B., Maltseva E.V., Gresov A.I., Telegin Y.A. Conditions of gas hydrate formation in the Sea of Okhotsk. Doklady Earth Sciences, 2014, vol. 454, no 1, pp. 94-96.

2. Andreassen K., Hubbard A., Winsborrow M., Patton H., Vadakkepuliyambatta S., Plaza-Faverola A., Gudlaugsson E., Serov P., Deryabin A., Mattingsdal R., Mienert J., Bunz S. Massive blow-out craters formed by hydrate-controlled methane expulsion from the Arctic seafloor. Science, 2017, vol. 356, no. 6341 , pp. $948-952$.

3. Greinert J., Artemov Y., Egorov V., De Batist M., McGinnis D. $1300-\mathrm{m}$-high rising bubbles from mud volcanoes at $2080 \mathrm{~m}$ in the Black Sea: Hydroacoustic characteristics and temporal variability. Earth and Planetary Science Letters, 2006, vol. 244, no. 1-2, pp. 1-15.

4. Greinert J., Bialas J., Lewis K., Suess E. Methane seeps at the Hikurangi Margin, New Zealand. Marine Geology, 2010, vol. 272, no. $1-4$, pp. $1-3$.

5. James R.H., Bousquet P., Bussmann I., Haeckel M., Kipfer R. Leifer I., Niemann H., Ostrovsky I., Piskozub J., Rehder G., Treude T., Vielstadte L., Greinert J. Effects of climate change on methane emissions from seafloor sediments in the Arctic Ocean: a review. Limnology and Oceanography, 2016, vol. 61, pp. S283-S299.

6. Leifer I., Patro R.K. The bubble mechanism for methane transport from the shallow sea bed to the surface: a review and sensitivity study. Continental Shelf Research, 2002, vol. 22, no. 16, pp. 2409-2428.

7. Makarov M., Muyakshin S., Kucher K., Aslamov I., Granin N A study of the gas seep Istok in the Selenga shoal using active acoustic, passive acoustic and optical methods. Journal of Great Lakes Research, 2020, vol. 46, pp. 95-101

8. Salomatin A.S., Yusupov V.I. Acoustic investigations of gas «Flares» in the Sea of Okhotsk. Oceanology, 2011, vol. 51, no. 5, pp. 857-865.

9. Sauer S., Hong W.-L., Yao H., Lepland A., Klug M., Eichinger F., Himmler T., Crémière A., Panieri G., Schubert C. J., Knies J. Methane transport and sources in an Arctic deep-water cold seep offshore NW Svalbard (Vestnesa Ridge, $79^{\circ} \mathrm{N}$ ). Deep Sea Research Part I: Oceanographic Research Papers, 2021, vol. 167, pp. 103430

10. Avdeyko G.P., Gavrilenko G.M., Chertkova L.V «Vulkanolog» issleduet podvodny fakel (o geologicheskikh izyskaniyakh nauchno-issledovatelskogo sudna v Tikhom okeane) [«Volcanologist» examines an underwater torch (on geological surveys of a research vessel in the Pacific Ocean)]. Priroda, 1986, vol. 7 , pp. $80-87$

11. Shakhova N., Semiletov I., Chuvilin E. Understanding the permafrost-hydrate system and associated methane releases in the East Siberian Arctic shelf. Geosciences, 2019, vol. 9, pp. 1-23.

12. Hovland M., Judd A., Burke R. The global flux of methane from shallow submarine sediments. Chemosphere, 1993, vol. 26, pp. 559-578.

13. Chuvilin E., Ekimova V., Davletshina D., Sokolova N., Bukhanov B. Evidence of gas emissions from permafrost in the Russian Arctic. Geosciences, 2020, vol. 10, no. 10. Available at: https://www.researchgate.net/publication/344363803_Evidence_of _Gas_Emissions_from_Permafrost_in_the_Russian_Arctic (accessed 26 July 2021)

14. Myrvoll-Nilsen E., Sørbye S.H., Fredriksen H.B., Rue H., Rypdal M. Statistical estimation of global surface temperature response to forcing under the assumption of temporal scaling. Earth Syst. Dynam., 2020, vol. 11, no. 2, pp. 329-345.

15. Thornes J.E. IPCC, 2001: climate change 2001: impacts, adaptation and vulnerability. Contribution of Working Group II to the Third Assessment Report of the Intergovernmental Panel on
Climate Change. International Journal of Climatology, 2002, vol. 22 , no. 10, pp. 1285-1286.

16. Climate change 2007: the physical science basis. Contribution of Working Group I to the Fourth Assessment Report of the Intergovernmental Panel on Climate Change. Cambridge, New York, Cambridge University Press, 2007. Available at: https://www. ipcc.ch/report/ar4/wg1/ (accessed 26 July 2021).

17. Edenhofer O., Madruga R.P., Sokona Y., Seyboth K., Matschoss P., Kadner S., Zwickel T., Eickemeier P., Hansen G., Schlömer S., Stechow C. Renewable energy sources and climate change mitigation: special report of the intergovernmental panel on climate change. Renewable Energy Sources and Climate Change Mitigation: Special Report of the Intergovernmental Panel on Climate Change, 2011. 075 p. Available at: https://www.ipcc.ch/report/ renewable-energy-sources-andclimate-change-mitigation/ (accessed 26 July 2021).

18. Shindell D., Faluvegi G., Koch D., Schmidt G., Unger N., Bauer S. Improved Attribution of Climate Forcing to Emissions. Science, 2009, vol. 326, pp. 716-718.

19. Chernykh D., Yusupov V., Salomatin A., Kosmach D., Shakhova N., Gershelis E., Konstantinov A., Grinko A., Chuvilin E., Dudarev O, Koshurnikov A., Semiletov I. Sonar estimation of methane bubble flux from thawing subsea permafrost: a case study from the Laptev sea shelf. Geosciences, 2020, vol. 10, no. 10, 411.

20. Ginsburg G.D., Soloviev V.A., Cranston R.E., Lorenson T.D., Kvenvolden K.A. Gas hydrates from the continental slope, offshore Sakhalin Island, Okhotsk Sea. Geo-Marine Letters, 1993, vol. 13 , no. 1, pp. 41-48.

21. Granin N., Muyakshin S., Makarov M., Kucher K., Aslamov I., Granina L., Mizandrontsev I. Estimation of methane fluxes from bottom sediments of Lake Baikal. Geo-Marine Letters, 2012, vol. 32, pp. 427-436.

22. Salomatin A.S., Yusupov V.I., Vereshchagina O.F., Chernykh D.V An acoustic estimate of methane concentration in a water column in regions of methane bubble release. Acoustical Physics, 2014, vol. 60, no. 6, pp. 671-677.

23. Veloso M., Greinert J., Mienert J., De Batist M. A new methodology for quantifying bubble flow rates in deep water using splitbeam echosounders: examples from the Arctic offshore NWSvalbard. Limnology and Oceanography-Methods, 2015, vol. 13, no. 6, pp. 267-287.

24. Leifer I., Chernykh D., Shakhova N., Semiletov I. Sonar gas flux estimation by bubble insonification: application to methane bubble flux from seep areas in the outer Laptev Sea. Cryosphere, 2017, vol. 11 , no. 3, pp. 1333-1350.

25. Mitchell G.A., Orange D.L., Gharib J.J., Kennedy P. Improved detection and mapping of deepwater hydrocarbon seeps: optimizing multibeam echosounder seafloor backscatter acquisition and processing techniques. Marine Geophysical Research, 2018, vol. 39, no. 1-2, pp. 323-347.

26. Urban P., Köser K., Greinert J. Processing of multibeam water column image data for automated bubble/seep detection and repeated mapping. Limnology and Oceanography: Methods, 2017, vol. 15 , no. 1, pp. 1-21.

27. Römer M., Hsu C.-W., Loher M., Macdonald I., Ferreira C., Pape T., Mau S., Bohrmann G., Sahling H. Amount and fate of gas and oil discharged at $3400 \mathrm{~m}$ water depth from a natural seep site in the Southern Gulf of Mexico. Frontiers in Marine Science, 2019, vol. 6. Available at: https://www.researchgate.net/publication/ 337300257_Amount and_Fate_of_Gas_and_Oil_Discharged_at 3 400_m_Water_Depth_From_a_Natural_Seep_Site_in_the_Souther n_Gulf_of_Mexico (accessed 26 July 2021).

28. Kasatkin S.A., Obzhirov A.I. Fluid-controlling significance of the Nosappu fracture zone and conditions for the formation of methane fluxes and gas hydrates (Sea of Okhotsk region). Russian Journal of Pacific Geology, 2018, vol. 12, no. 1, pp. 57-62. 
29. Shakirov R.B., Obzhirov A.I., Salomatin A.S., Makarov M.M New data on lineament control of modern centers of methane degassing in East Asian Seas. Doklady Earth Sciences, 2017, vol. 477, no. 1, pp. 1287-1290.

30. Kim Y.G., Lee S.M., Jin Y.K., Baranov B., Obzhirov A., Salomatin A., Shoji H. The stability of gas hydrate field in the northeastern continental slope of Sakhalin Island, Sea of Okhotsk, as inferred from analysis of heat flow data and its implications for slope failures. Marine and Petroleum Geology, 2013, vol. 45, pp. 198-207.

31. Obzhirov A.I., Emelyanova T.A., Telegin Y.A., Shakirov R.B. Gas flows in the Sea of Okhotsk resulting from CretaceousCenozoic tectonomagmatic activity. Russian Journal of Pacific Geology, 2020, vol. 14, no. 2, pp. 156-168.

32. Matveeva T., Solov'ev V.A. Gas hydrates in Sea of Okhotsk: regularities in formation and distribution. Lithology and Mineral Resources, 2003, vol. 47, pp. 101-112.

33. Hans N.C., Thor D.R., Sandstrom M.W. Kvenvolden K.A. Modern biogenic gas-generated craters (sea-floor «pockmarks») on the Bering Shelf, Alaska. GSA Bulletin, 1979, vol. 90, no. 12 , pp. 1144-1152.

34. Volovov I.V. Otrazhenie zvuka ot dna okeana [Sound reflection from the ocean bottom]. Moscow, Nauka Publ., 1993. 272 p.

35. Weidner E., Weber T. C., Mayer L., Jakobsson M., Chernykh D. Semiletov I. A wideband acoustic method for direct assessment of bubble-mediated methane flux. Continental Shelf Research, 2019, vol. 173, pp. 104-115.

36. Bogoyavlensky V., Kishankov A., Yanchevskaya A., Bogoyavlensky I. Forecast of gas hydrates distribution zones in the Arctic Ocean and adjacent offshore areas. Geosciences, 2018, vol. 8, no. 12, pp. 1-17.

37. Operation report of Sakhalin slope gas hydrate project 2007, R/V "Akademik M.A. Lavrentyev» Cruise 43. Kitami, Japan, Kitami Institute of Technology, 2008. $39 \mathrm{p}$.

38. Obzhirov A.I., Sokolova N.L., Telegin Y.A. Geological conditions of the formation and dissociation of gas hydrates in the Sea of Okhotsk: tectonic and genetic aspects. Lithology and mineral resources, 2021, vol. 56, no. 4, pp. 333-342.
39. The Earthquake Hazards Program Website is Moving. Docslide. 2021. Available at: https://earthquake.usgs.gov (accessed 23 February 2021).

40. Chebrov V.N., Kugaenko Yu.A., Vikulina S.A., Kravchenko N.M., Matveenko E.A., Mityushkina S.V., Raevskaya A.A., Saltykov V.A., Chebrov D.V., Lander A.V. Glubokoe okhotomorskoe zemletryasenie $24.05 .2013 \mathrm{~g}$. s magnitudoy $\mathrm{mw}=8,3$ - silneyshee seysmicheskoe sobytie u beregov Kamchatki za period detalnykh seysmologicheskikh nablyudeniy [Deep Sea of Okhotsk earthquake on May 24, 2013 with a magnitude of $m w=8,3-$ the strongest seismic event off the coast of Kamchatka during the period of detailed seismological observations]. Vestnik KRAUNTS. Nauki o Zemle, 2013, vol. 21, pp. 17-24.

41. Kutas R.I., Paliy S.I., Rusakov O.M. Deep faults, heat flow and gas leakage in the northern Black Sea. Geo-Marine Lett., 2004, vol. 24, pp. 163-168.

42. Parovyshny V.A., Senachin V.N., Veselov O.V., Kochergin E.V. Temporal variations in geophysical fields and earthquake forecasting issues. Geodynamics \& Tectonophysics, 2015, vol. 6, no. 1 , pp. $63-76$.

43. Shakhova N.E., Alexeev V.A., Semiletov I.P. Predicted methane emission on the East Siberian shelf. Doklady Earth Sciences, 2010, vol. 430 (2), pp. 190-193.

44. Shakhova N.E., Sergienko V.I., Semiletov I.P. Modern state of the role of the East Siberian Shelf in the methane cycle. Herald of the Russian Academy of Sciences, 2009, vol. 79, no. 6, pp. 507-518.

45. Shakhova N.E., Nicolsky D., Semiletov I.P. Current state of subsea permafrost on the East-Siberian Shelf: tests of modeling results based on field observations. Doklady Earth Sciences, 2009, vol. 429 (2), pp. 1518-1521.

46. Shakhova N., Semiletov I., Sergienko V., Lobkovsky L., Yusupov V., Salyuk A., Salomatin A., Chernykh D., Kosmach D., Panteleev G., Nicolsky D., Samarkin V., Joye S., Charkin A., Dudarev O., Meluzov A., Gustafsson Ö. The East Siberian Arctic Shelf: towards further assessment of permafrost-related methane fluxes and role of sea ice. Philosophical Transactions of the Royal Society A, 2015, vol. 373, no. 2052, 20140451

Received 4 August 2021.

\section{Information about the authors}

Denis V. Chernykh, Cand. Sc., researcher, Russian Academy of Sciences, Pacific Oceanological Institute.

Alexander S. Salomatin, Cand. Sc., head of the Laboratory, Russian Academy of Sciences, Pacific Oceanological Institute.

Vladimir I. Yusupov, Cand. Sc., senior researcher, Russian Academy of Sciences Institute of Photon Technologies, Federal Scientific Research Centre «Crystallography and Photonics».

Natalia E. Shakhova, Dr. Sc., professor, chief researcher, Laboratory of Arctic Research, Russian Academy of Sciences, Pacific Oceanological Institute; chief researcher, Higher School of Economics

Denis A. Kosmach, researcher, Russian Academy of Sciences, Pacific Oceanological Institute.

Oleg V. Dudarev, Dr. Sc., chief researcher, Russian Academy of Sciences, Pacific Oceanological Institute

Elena V. Gershelis, Cand. Sc., associate professor, National Research Tomsk Polytechnic University,

Vyacheslav I. Silionov, lead engineer, Russian Academy of Sciences, Pacific Oceanological Institute

Roman A. Ananiev, researcher, Shirshov Institute of Oceanology, Russian Academy of Sciences

Igor P. Semiletov, Corresponding Member of the Russian Academy of Sciences, Dr. Sc., professor, head of the Laboratory of Arctic Research, Russian Academy of Sciences, Pacific Oceanological Institute; principal investigator, National Research Tomsk Polytechnic University.

Andrey A. Grinko, Cand. Sci., engineer, National Research Tomsk Polytechnic University. 